\title{
Prognostic Value of Cardiopulmonary Exercise Test in Elderly Women with Heart Failure and Reduced or Preserved Ejection Fraction
}

\author{
Angela Beatrice Scardovi ${ }^{*}$, Renata De Maria ${ }^{2}$, Alessandro Ferraironi ${ }^{1}$, Marco Renzi ${ }^{1}$, \\ Franco Turi' ${ }^{1}$ Marina Parolini'2, Tiziana Di Giacomo', Roberto Ricci1 \\ ${ }^{1}$ Cardiology Department, S. Spirito Hospital, Rome, Italy \\ ${ }^{2}$ CNR Clinical Physiology Institute, Cardio Thoracic and Vascular Department, Niguarda Hospital, Milan, Italy \\ Email: ${ }^{*}$ ab.scardovi@libero.it
}

Received 15 April 2014; revised 20 May 2014; accepted 28 May 2014

Copyright (C) 2014 by authors and Scientific Research Publishing Inc. This work is licensed under the Creative Commons Attribution International License (CC BY). http://creativecommons.org/licenses/by/4.0/

c) (i) Open Access

\section{Abstract}

The prognostic role of cardiopulmonary exercise test (CPET) in elderly women with chronic heart failure (HF) has not yet been clarified. We assessed the incremental value of CPET variables for risk stratification in female HF patients with preserved or reduced left ventricular ejection fraction (LVEF). We prospectively followed up 131 female HF outpatients aged 72 [interquartile range 62 - 77] years after a symptom limited CPET. 34\% had ischemic heart disease and $14 \%$ permanent atrial fibrillation, $24 \%$ were in NYHA class III. LVEF was $50 \%$ [interquartile range 36 - 62], peak oxygen consumption was 11.3 [interquartile range $9.2-13.5$ ] $\mathrm{ml} / \mathrm{kg} / \mathrm{min}$; the slope of the regression line relating ventilation to $\mathrm{CO}_{2}$ output was 33.9 [interquartile range $30.3-44.9$ ]; $40 \%$ of patients showed exercise oscillatory breathing during CPET. During a median follow-up of 18 months [interquartile range 8 - 54], overall 39 patients $(29.7 \%)$ met the combined end-point of cardiovascular mortality or HF admission using a time-to-first event approach. Moderate to severe mitral regurgitation, slope, exercise oscillatory breathing were independently associated to cardiovascular mortality or HF admission. When CPET ventilatory variables were added to clinical and echocardiographic parameters, prediction of the combined point improved significantly (AUC 0.755 (95\% CI 0.662 to 0.832 ) vs 0.634 (95\% CI 0.536 to 0.725$), p=0.016)$. In conclusion, among elderly female HF patients the CPET derived parameters EOB and VE/ $\mathrm{VCO}_{2}$ slope emerged as strong prognostic markers, with additive predictive value to clinical and echocardiographic parameters in patients with both reduced and preserved LVEF.

\footnotetext{
"Corresponding author.
} 


\section{Keywords}

\section{Women, Heart Failure, Cardiopulmonary Exercise Test, Ventilatory Inefficiency}

\section{Introduction}

The natural history of heart failure (HF) is different in women and men. In women, HF which develops later in life, is more often attributable to hypertension and less frequent to coronary disease and is more often associated with preserved ventricular function than that in men [1]. Although women with HF have been reported to survive longer [2]-[4], they are admitted to hospital more frequently [5] [6] and present with more severe symptoms than men [3].

The cardiopulmonary exercise test (CPET) provides simultaneous assessment of the performance of the heart, lungs, muscles and cellular respiration during physical exercise and is one of the most reliable tools to select candidates for heart transplantation. Beyond this established role for risk stratification in HF patients, the longterm prognostic value of CPET in women suffering from HF has not yet been deeply explored.

Our study aimed to assess the prognostic value of ventilatory variables for a composite of cardiovascular mortality and HF admissions in a cohort of elderly women with HF and reduced or preserved systolic function.

\section{Methods}

We studied female patients with a clinical diagnosis of HF based on European Society of Cardiology [7] criteria who were consecutively evaluated at the CPET laboratory of our institution between 2006 and 2011. Patients with both reduced (HFrEF) and preserved (HFpEF) left ventricular ejection fraction (LVEF) were included; patients with preserved ( $>50 \%$ ) LVEF had to show signs of congestion on chest X-ray or a BNP value $>100 \mathrm{pg} / \mathrm{ml}$ and echocardiographic evidence of diastolic dysfunction [7].

Patients were in NYHA class II-III, on stable pharmacological treatment since at least three months and none of them was a heart transplant candidate. The indication to CPET was risk stratification and clinical decisionmaking for follow-up planning. Patients were included in the study if they were able to perform a CPET test with a respiratory exchange ratio $>1.00$, indicating the achievement of anaerobic exercise conditions. Among 293 considered patients, 82 were ineligible for clinical contraindications to exercise (severe aortic stenosis $(n=$ $10)$; severe pulmonary disease $(n=6)$; orthopedic $(n=65)$ problems; recent onset atrial fibrillation $(n=1))$; 80 were excluded for a respiratory exchange ratio $<1.00$.

All patients received routine follow-up care. Outcome data of patients who did not attend their scheduled appointments were obtained by telephone interview of the patient or her family: during the follow-up time, none of these patients had been admitted to the hospital. The study was approved by the Institutional Review Board. Subjects signed a written informed consent to the use of their data for scientific purposes.

Standard symptom-limited CPET was performed by cycle ergometry ramping [8]. Analysis was performed with a metabolic cart (Sensor Medics Vmax 29, Yorba Linda, Calif). Before each test, the equipment was calibrated in standard fashion with reference gases. Standard 12-lead ECGs were obtained at rest, each minute during exercise, and for at least 5 minutes during the recovery phase. Blood pressure was measured with a standard cuff sphygmomanometer. Minute ventilation (VE), oxygen uptake $\left(\mathrm{VO}_{2}\right)$, carbon dioxide output $\left(\mathrm{VCO}_{2}\right)$, and other cardiopulmonary variables were acquired on a breath-by-breath basis and averaged over 10-second intervals. Peak $\mathrm{VO}_{2}\left(\mathrm{PVO}_{2}\right)$ and peak RER were expressed as the highest averaged samples obtained during the exercise test. VE and $\mathrm{VCO}_{2}$ values were acquired from the initiation of exercise to peak exercise. For the calculation of the slope of minute ventilation/carbon dioxide production linear relationship ( $\mathrm{VE} / \mathrm{VCO}_{2}$ slope), we measured all data points from the beginning to the end of exercise [9]. Exercise oscillatory breathing (EOB) was assessed using criteria previously reported by Leite et al. [10].

Standard M-mode and two-dimensional echocardiography and Doppler blood flow measurements were performed in agreement with the American Society of Echocardiography guidelines [11] [12]. Early and late diastolic mitral peak flow velocity (E, A) and E-wave deceleration time were assessed by pulsed-wave Doppler echocardiography. Mitral regurgitation was quantitated on a 4-grade (absent, mild, moderate, severe) scale by color-Doppler assessment. In case of at least moderate regurgitation, the PISA method quantification was at- 
tempted and insufficiency was classified as severe in the presence of regurgitant surface area $\geq 0.25 \mathrm{~cm}^{2}$ and/or $\geq 40 \mathrm{~mL}$ regurgitant blood volume [11] [12].

\section{Statistical Analysis}

Categorical variables are presented as frequency percent and continuous variables as median values [interquartile range]. Between-group differences were tested by chi-square test and Student's $t$-test or non parametric testing according to normal or non normal variable distribution. Study end-point was the combination of cardiovascular mortality or hospital admission for worsening HF. To determine the independent predictors of outcome, we entered variables significant by univariable analysis $(p<0.05)$ in multivariable Cox proportional hazards models. Non categorical variables were dichotomized using literature reference cut offs. Hazard ratios (HR) are presented with 95\% confidence intervals (CI). To estimate if the sample size was appropriate for the specific tests, a statistical power analysis [13] was performed ex-post on the main predictors identified and adjusted by the other covariates and the estimated event rate.

Model discrimination was then tested using the c statistic and expressed as area under the ROC curve (AUC). First we derived models including clinical and echocardiographic variables; then we assessed changes in AUC after entering CPET parameters by the method of De Long et al. [14]. A $p$ value $<0.05$ was considered statistically significant. All statistical tests were two-tailed. Data were analyzed using The Statistical Package for the Social Sciences SPSS 20.

\section{Results}

We studied 131 stable female HF outpatients after implementation of recommended drug therapy including renin-angiotensin system inhibitors in 131 (100\%) and beta-blockers in 64 (50\%). Cardiac resynchronization therapy and a cardioverter defibrillator had been previously implanted in 5 patients (4\%) who met guideline indications for device therapy.

Clinical characteristics and CPET parameters by LV function are summarized in Table 1. Patients with HFpEF and HFrEF had similar age, symptom severity, body mass index, prevalence of atrial fibrillation, achieved workload and $\mathrm{VE} / \mathrm{VCO}_{2}$ slope. Patients with $\mathrm{HFrEF}$ showed a higher prevalence of ischemic etiology, left bundle branch block, beta-blocker treatment, moderate-to-severe mitral regurgitation, EOB than subjects with HFpEF.

During a median follow-up of 18 [interquartile range 8 - 54] months, 20 patients died, 18 (14\%) of cardiovascular causes (pump failure 8, sudden death 6, acute myocardial infarction 6) and 2 of cancer, whereas 41 subjects were admitted for worsening HF. Using a time-to-first event approach, overall 39 patients (29.7\%) met the combined end-point of cardiovascular mortality or HF admission. Variables significantly associated to the combined endpoint by univariable analysis (Table 2) were dichotomized and sequentially entered into multivariable Cox models first combining clinical and echocardiographic variables (model 1) and then adding CPET variables (model 2) (Table 3). A Cox regression of the log hazard ratio on a covariate with a standard deviation of 0.444 based on a sample of 130 patients achieves, at a 0.05 significance level, $86 \%$ power to detect a regression coefficient equal to 1.22 and achieves $89 \%$ power to detect a regression coefficient equal to 1.283 . The sample size was adjusted since a multiple regression of the main variables of interest on the other covariates (VE/ $/ \mathrm{VO}_{2}$ slope, atrial fibrillation, LVEF, NYHA class, watts achieved) is expected to have an R-Squared of 0.1130 .

In adjusted model 2, the hazard ratio for coexistent $\mathrm{EOB}$ and $\mathrm{VE} / \mathrm{VCO}_{2}$ slope $>36$ was 8.08 (95\% CI 3.01 to 21.7). Adjusted survival rates free from HF admission for patients with neither EOB nor $\mathrm{VE} / \mathrm{VCO}_{2}$ slope $>36$, either or both ventilatory abnormalities are shown in Figure 1.

We tested the incremental predictive value of adding CPET variables (model 2) to the model including clinical and echocardiographic parameters (model 1): AUC values of model 1 and 2 were 0.634 (95\% CI 0.536 to $0.725)$, and 0.755 (95\% CI 0.662 to 0.832$)$, respectively $(p=0.016)$.

\section{Discussion}

We compared the prognostic value of CPET variables in female patients with HFrEF vs HFpEF. To the best of our knowledge, this is the first report on a large population of elderly HF women to compare the additive predic- 
Table 1. Clinical characteristics of the study population.

\begin{tabular}{|c|c|c|c|c|}
\hline Variable & All $n=131$ & HFrEF $n=61$ & HFpEF $\quad n=70$ & $p$ value \\
\hline Ischemic etiology & $44(34)$ & $27(44)$ & $17(24)$ & 0.017 \\
\hline NYHA class III & $31(24)$ & $12(21)$ & $19(27)$ & 0.41 \\
\hline Atrial fibrillation & $18(14)$ & $8(13)$ & $10(15)$ & 1.000 \\
\hline Left bundle branch block & $31(26)$ & $26(47)$ & $5(8)$ & 0.001 \\
\hline Beta-blockers & $64(50)$ & $37(62)$ & $27(40)$ & 0.01 \\
\hline Age (years) & 72 [62 - 77] & $72[62$ - 77] & $71[64-79]$ & 0.82 \\
\hline Body mass index & $24.2[22.0-27.7]$ & 24.2 [21.7 - 28.9] & $24.0[22.0-27.6]$ & 0.85 \\
\hline LVEF (\%) & $50[36-62]$ & $35[30-41]$ & $61[55-66]$ & - \\
\hline E/A ratio & $0.77[0.62-142]$ & $0.72[0.59-1.84]$ & $0.80[0.66-1.29]$ & 0.35 \\
\hline Deceleration time & 202 [156 - 249] & $185[130-240]$ & 209 [175 - 255] & 0.26 \\
\hline Restrictive filling pattern & 21(16) & $14(23)$ & $7(10)$ & 0.057 \\
\hline Moderate to severe MR & $29(23)$ & $19(33)$ & $10(15)$ & 0.032 \\
\hline Workload (Watt) & $52[40-66]$ & $50[37-60]$ & $57[42-71]$ & 0.15 \\
\hline Peak $\mathrm{VO}_{2}(\mathrm{ml} / \mathrm{kg} / \mathrm{min})$ & $11.3[9.2-13.5]$ & $11.0[9.0-12.5]$ & $11.6[9.6-14]$ & 0.33 \\
\hline$\%$ Peak $\mathrm{VO}_{2}$ & $52[42-63]$ & $46[40-61]$ & $56[45-63]$ & 0.04 \\
\hline $\mathrm{VE} / \mathrm{VCO}_{2}$ slope & $33.9[30.3-41]$ & 34.9 [30.4 - 41.9] & $33.2[29-39.8]$ & 0.26 \\
\hline $\mathrm{VE} / \mathrm{VCO}_{2}$ slope $>36$ & $52(40)$ & $31(44)$ & $21(34)$ & 0.28 \\
\hline EOB & $52(40)$ & $36(51)$ & $16(31)$ & 0.004 \\
\hline
\end{tabular}

Data are presented as Median [interquartile range] or numbers (\%). A, Transmitral A Velocity; E, Transmitral E Velocity; EOB = Exercise Oscillatory Breathing; LBBB = Left Bundle Branch Block; LVEDVI = Left Ventricular End Diastolic Volume Index; LVEF = Left Ventricular Ejection Fraction; LVESVI = Left Ventricular End Systolic Volume Index; MR = Mitral Regurgitation; $\mathrm{PVO}_{2}=$ Peak Oxygen Uptake; \% PVO $\mathrm{P}_{2}=$ Percent Predicted $\mathrm{PVO}_{2} ; \mathrm{VE} / \mathrm{VCO}_{2}$ Slope = Slope of the Regression Line Relating VE to Carbon Dioxide Production.

tive value of CPET for prognosis stratifying by ventricular function. We found that ventilatory parameters, EOB and $\mathrm{VE} / \mathrm{VCO}_{2}$ slope, improved outcome prediction, independently of $\mathrm{LV}$ function, beyond established clinical and echocardiographic predictors atrial fibrillation and mitral regurgitation.

Our study describes the prognostic impact of ventilatory parameters in a "real world" female HF population, as demonstrated by the mean age (72 years) and proportion with HFpEF (54\%) generally neglected in HF trials.

In our female series, atrial fibrillation and mitral regurgitation were key prognostic determinants, consistently with previous reports, irrespective of sex [15]. HF and atrial fibrillation share the same risk factors and together have a negative synergic impact on prognosis [16], increasing mortality and morbidity both in hospitalised [17] and community patients [16] [18], irrespective of LV function [10] [20]. The unfavourable effect of atrial fibrillation on outcome may be even stronger in women [19] and in HFpEF [20].

On the other hand, global and local LV remodelling in HF is frequently associated with mitral regurgitation which in turn increases left atrial dilation and remodelling with enhanced risk of atrial fibrillation and clinical events [21].

CPET represent an important risk stratification tool in daily clinical practice even in elderly HF patients not eligible for heart transplant [22], in whom it is safe, feasible and prognostically reliable [23], provided that they are physically able to perform a maximal exercise test. Previous studies addressed gender differences among relatively young populations of heart transplant candidates. Elmariah et al. [24] examined the gender effects on $\mathrm{PVO}_{2}$ and survival in 594 ambulatory HF patients (28\% women) and concluded that women had a significantly 
Table 2. Univariable predictors of death or HF admission.

\begin{tabular}{|c|c|c|c|}
\hline & $p$ value & HR & $95 \% \mathrm{CI}$ \\
\hline EOB & 0.001 & 3.77 & $1.87-7.32$ \\
\hline NYHA class III & 0.02 & 3.27 & $1.56-6.89$ \\
\hline Moderate-severe MR & 0.01 & 3.15 & $1.56-6.36$ \\
\hline Atrial fibrillation & 0.007 & 2.73 & $1.31-5.67$ \\
\hline $\mathrm{VE} / \mathrm{VCO}_{2}$ slope & 0.001 & 1.07 & $1.04-1.10$ \\
\hline Watt & 0.04 & 0.98 & $0.96-0.99$ \\
\hline Age & 0.12 & 1.03 & $0.99-1.06$ \\
\hline LVEF & 0.69 & 0.98 & $0.95-1.00$ \\
\hline LBBB & 0.10 & 1.79 & $0.89-3.57$ \\
\hline BMI & 0.15 & 0.94 & $0.87-1.02$ \\
\hline Peak $\mathrm{VO}_{2}$ & 0.17 & 0.93 & $0.83-1.03$ \\
\hline Ischemic etiology & 0.15 & 0.62 & $0.32-1.19$ \\
\hline E/A ratio & 0.11 & 1.37 & $0.93-2.03$ \\
\hline Deceleration time & 0.21 & 0.99 & $0.99-1.00$ \\
\hline Beta-blockers & 0.95 & 1.02 & $0.53-1.94$ \\
\hline$\%$ Peak $\mathrm{VO}_{2}$ & 0.63 & 0.99 & $0.97-1.01$ \\
\hline Restrictive filling pattern & 0.12 & 1.95 & $0.84-4.53$ \\
\hline
\end{tabular}

For abbreviations see Table 1.

Table 3. Cox regression analysis of clinical echocardiographic and ventilatory variables with cardiovascular mortality or heart failure admission.

\begin{tabular}{|c|c|c|c|c|}
\hline & $p$ value & beta & HR & $95 \%$ CI \\
\hline \multicolumn{5}{|l|}{ Clinical + echo (model 1) } \\
\hline Moderate to severe mitral regurgitation & 0.003 & 1.152 & 3.16 & $1.49-6.73$ \\
\hline Atrial fibrillation vs sinus rhtyhm & 0.024 & 1.068 & 2.91 & $1.15-7.34$ \\
\hline NYHA class III vs I-II & 0.800 & 0.700 & 2.01 & $0.92-4.41$ \\
\hline LVEF $>50 \%$ vs $<50 \%$ & 0.603 & 0.194 & 0.82 & $0.39-1.71$ \\
\hline \multicolumn{5}{|l|}{ Clinical + echo + CPET (model 2) } \\
\hline Moderate to severe mitral regurgitation & 0.001 & 1.283 & 3.61 & $1.64-7.93$ \\
\hline EOB & 0.002 & 1.220 & 3.39 & $1.58-7.26$ \\
\hline $\mathrm{VE} / \mathrm{VCO}_{2}$ slope $>36$ vs $<36$ & 0.012 & 0.973 & 2.65 & $1.23-6.57$ \\
\hline Atrial fibrillation vs sinus rhtyhm & 0.08 & 0.897 & 2.45 & $0.89-6.77$ \\
\hline NYHA class III vs I-II & 0.95 & 0.025 & 1.03 & $0.41-2.59$ \\
\hline LVEF $>50 \%$ vs $<50 \%$ & 0.11 & -0.636 & 0.53 & $0.24-1.15$ \\
\hline Workload achieved $>50$ vs $<50$ watts & 0.96 & -0.019 & 0.98 & $0.45-2.12$ \\
\hline
\end{tabular}

CPET = Cardiopulmonary exercise test. For other abbreviations see Table 1. 


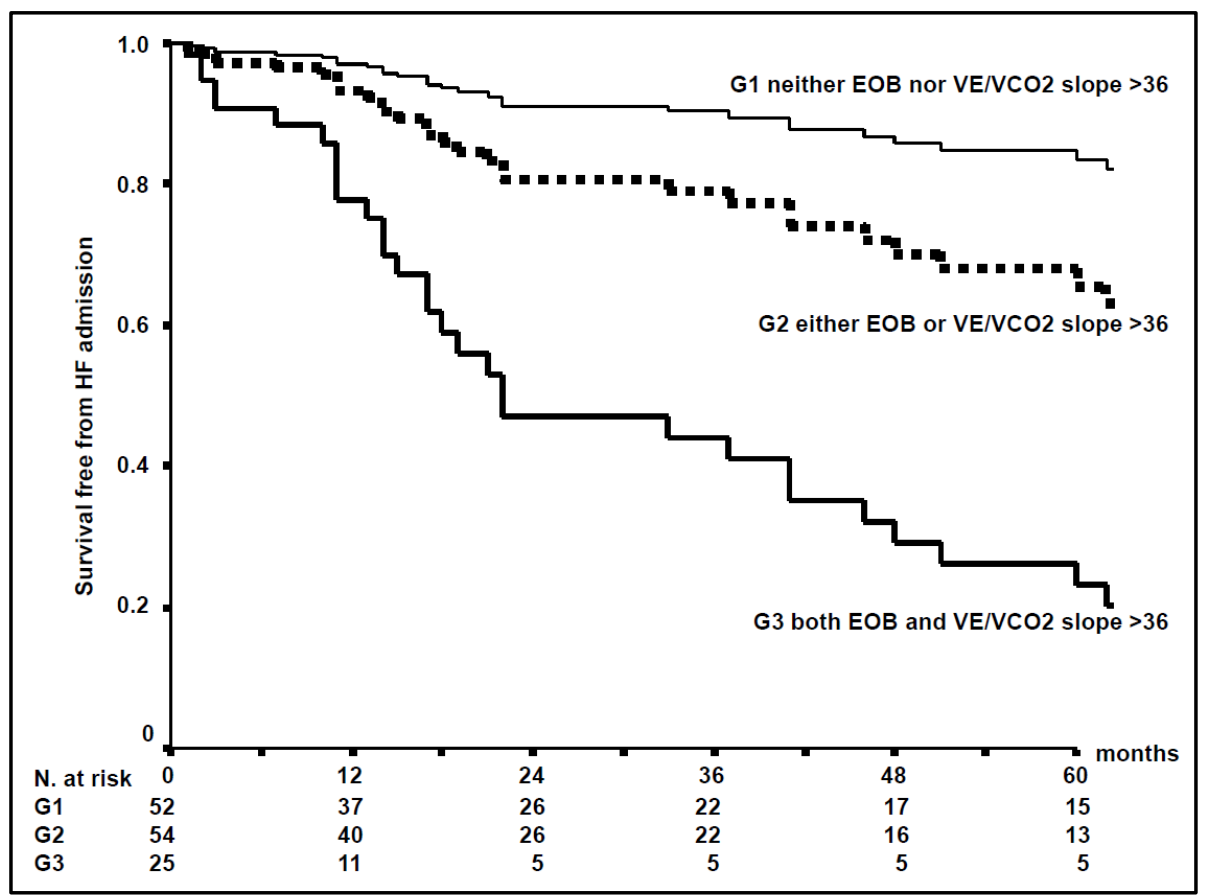

Figure 1. Curves depicting survival free from heart failure admission in relation to absence or presence of one or both ventilatory abnormalities associated with outcome by Cox regression analysis. EOB, exercise oscillatory breating; $\mathrm{VE} / \mathrm{VCO}_{2}$ slope, slope of the regression line relating ventilation to $\mathrm{CO}_{2}$ output.

lower $\mathrm{PVO}_{2}$ than men, but had better survival at all levels of exercise capacity and suggested to re-examine the current practice of uniform application of $\mathrm{PVO}_{2}$ as an aid for transplant timing. This study focused on relatively young female transplant candidates and did not take into account novel ventilatory parameters, such as ventilatory efficiency assessed by the $\mathrm{VE} / \mathrm{VCO}_{2}$ slope during CPET, and EOB. Corrà et al. [25] evaluated gender differences in $\mathrm{PVO}_{2}$ in $529 \mathrm{HF}$ patients (22\% women) concluding that in women with HF cut-off $\mathrm{PVO}_{2}$ values useful for risk stratification should be redefined. Guazzi et al. [26] demonstrated that the prognostic value of $\mathrm{PVO}_{2}$ and $\mathrm{VE} / \mathrm{VCO}_{2}$ slope is similar in men and women with $\mathrm{HF}$ and that in both genders the prognostic power of $\mathrm{VE} / \mathrm{VCO}_{2}$ slope is greater than that of $\mathrm{PVO}_{2}$. Both studies involved women younger than ours (mean age 60 years and 55 years, respectively) and did not consider the incidence and the prognostic weight of EOB.

In a former study among 370 elderly HF patients (29\% female), we found a higher EOB prevalence than previously reported in middle-aged cohorts. EOB and the ratio of $\mathrm{VE} / \mathrm{VCO}_{2}$ slope to $\mathrm{PVO}_{2}$ emerged as the strongest ventilatory predictors of all-cause mortality, independently of ventricular function [27].

EOB is a cyclic breathing pattern that reflects a severe derangement of the ventilatory control system [27]. In previous studies in middle-aged male patient cohorts [28]-[30], prevalence of EOB ranged from $12 \%$ to $35 \%$ In the only study conducted in patients with diastolic HF [31], EOB was as common as in subjects with systolic dysfunction. In our population, the prevalence of EOB, which has not been previously specifically explored in female HF patients, was $40 \%$, distinctly higher than values reported in transplant candidates $(20 \%-30 \%)$.

The novelty of our study resides first in the population analysed: while women represent over one half of HF patients in the community and show a peculiar phenotype with predominantly preserved LVEF, risk stratification using CPET has been seldom described in a sizable cohort for this patient group. The study by Corrà et al. [30] included only 8 women, whereas other reports analysed female cohorts that, although larger, were definitely younger than our patients [28] [29]. Furthermore none of these studies [28]-[30] compared, within the female group, patient with preserved and reduced LVEF. Our findings demostrate that ventricular function does not independently predict prognosis when compaed with ventilatory variables.

We confirmed that prognosis, even for stable female outpatients, is poor: in the medium term one third of patients either died for cardiovascular reasons or was admitted for HF. In agreement with previous data [28]-[31], the ventilatory parameters $\mathrm{EOB}$ and $\mathrm{VE} / \mathrm{VCO}_{2}$ slope, emerged as the strongest $\mathrm{CPET}$ predictors of outcome in 
our series, both contributing incremental prognostic value independently of LVEF. We confirmed in elderly women the lack of independent prognostic value of $\mathrm{PVO}_{2}$ [26] [27] [30] [31]. CPET-derived variables showed an incremental prognostic power when added to clinical and echocardiographic parameters, with very good predictive accuracy as described by the $\mathrm{C}$ statistic of 0.755 .

\subsection{Clinical Implications}

The coexistence of ventilatory inefficiency, characterized ed by EOB and incresed VE/ $\mathrm{VCO}_{2}$ slope, with moderate to severe mitral regurgitation, identifies, even among female patients, a population with severe circulatory and ventilatory instability, that is associated with a heavy burden of adverse events. Medical management for these women should be reviewed and optimized whenever possible and strict clinical follow-up should be envisaged to recognize early clinical signs of impending destabilization. Regular exercise training, in addition to evidence-based therapy, should be encouraged, on the basis of its safety and the documented decrease in clinical events and improvement in health-related quality of life [32], even in the elderly HF female patient.

\subsection{Study Limitations}

Our study population was relatively small and included only clinically stable "robust" female outpatients with mild to moderate HF, who did not have important comorbidities and were furthermore able to perform a CPET. We did not include a male patient control group. We did not perform serial CPET to investigate whether patients developed ventilatory abnormalities during follow-up and to assess the impact of optimized treatment on it.

In conclusion, the respiratory pattern during CPET represents a key marker of adverse outcome in female HF patients with both HfrEF and HFpEF. These findings prospect the utility of comprehensively assessing CPETderived information to optimize the clinical and prognostic work-up of women suffering from HF.

\section{Conflict of Interest}

The authors declare no conflict of interest.

\section{References}

[1] Hsich, E.M. and Piña, I.L. (2009) Heart Failure in Women: A Need for Prospective Data. Journal of the American College of Cardiology, 54, 491-498. http://dx.doi.org/10.1016/j.jacc.2009.02.066

[2] Levy, D., Kenchaiah, S., Larson, M.G., Benjamin, E.J., Kupka, M.J., Ho, K.K., Murabito, J.M. and Vasan, R.S. (2002) Long-Term Trends in the Incidence of and Survival with Heart Failure. The New England Journal of Medicine, 347, 1397-1402. http://dx.doi.org/10.1056/NEJMoa020265

[3] Martınez-Selles, M., Doughty, R.N., Poppe, K., Whalley, G.A., Earle, N., Tribouilloy, C., McMurray, J.J., Swedberg, K., Køber, L., Berry, C., Squire, I. and Meta-Analysis Global Group In Chronic Heart Failure (MAGGIC) (2012) Gender and Survival in Patients with Heart Failure: Interactions with Diabetes and Aetiology. Results from the MAGGIC Individual Patient Meta-Analysis. European Journal of Heart Failure, 14, 473-479. http://dx.doi.org/10.1093/eurjhf/hfs026

[4] Vaartjes, I., Hoes, A.W., Reitsma, J.B., et al. (2010) Age- and Gender-Specific Risk of Death after First Hospitalization for Heart Failure. BMC Public Health, 10, 637. http://dx.doi.org/10.1186/1471-2458-10-637

[5] Koelling, T.M., Chen, R.S., Lubwama, R.N., L’Italien, G.J. and Eagle, K.A. (2004) The Expanding National Burden of Heart Failure in the United States: The Influence of Heart Failure in Women. American Heart Journal, 147, 74-78. http://dx.doi.org/10.1016/j.ahj.2003.07.021

[6] Deswal, A. and Bozkurt, B. (2006) Comparison of Morbidity in Women versus Men with Heart Failure and Preserved Ejection Fraction. American Journal of Cardiology, 97, 1228-1231. http://dx.doi.org/10.1016/j.amjcard.2005.11.042

[7] ESC (2012) Guidelines for the Diagnosis and Treatment of Acute and Chronic Heart Failure 2012: The Task Force for the Diagnosis and Treatment of Acute and Chronic Heart Failure 2012 of the European Society of Cardiology. European Heart Journal, 33, 1787-1847. http://dx.doi.org/10.1093/eurheartj/ehs104

[8] Mezzani, A., Agostoni, P., Cohen-Solal, A., Corrà, U., Jegier, A., Kouidi, E., Mazic, S., Meurin, P., Piepoli, M., Simon, A., Laethem, C.V. and Vanhees, L. (2009) Standards for the Use of Cardiopulmonary Exercise Testing for the Functional Evaluation of Cardiac Patients. European Journal of Cardiovascular Prevention \& Rehabilitation, 6, 249-267. http://dx.doi.org/10.1097/HJR.0b013e32832914c8

[9] Arena, R., Myers, J., Aslam, S.S., Varughese, E.B. and Peberdy, M.A. (2003) Technical Considerations Related to the 
Minute Ventilation/Carbon Dioxide Output Slope in Patients with Heart Failure. Chest, 124, 720-727. http://dx.doi.org/10.1378/chest.124.2.720

[10] Leite, J.J., Mansur, A.J., de Freitas, H.F., Chizola, P.R., Bocchi, E.A., Terra-Filho, M., Neder, J.A. and Lorenzi-Filho, G. (2003) Periodic Breathing during Incremental Exercise Predicts Mortality in Patients with Chronic Heart Failure Evaluated for Cardiac Transplantation. Journal of the American College of Cardiology, 41, 2175-2178. http://dx.doi.org/10.1016/S0735-1097(03)00460-1

[11] Cheitlin, M.D., Armstrong, W.F., Aurigemma, G.P., Beller, G.A., Bierman, F.Z., Davis, J.L., Douglas, P.S., Faxon, D.P., Gillam, L.D., Kimball, T.R., Kussmaul, W.G., Pearlman, A.S., Philbrick, J.T., Rakowski, H., Thys, D.M., Antman, E.M., Smith Jr., S.C., Alpert, J.S., Gregoratos, G., Anderson, J.L., Hiratzka, L.F., Faxon, D.P., Hunt, S.A., Fuster, V., Jacobs, A.K., Gibbons, R.J., Russell, R.O., ACC, AHA and ASE (2003) Guideline Update for the Clinical Application of Echocardiography A Report of the American College of Cardiology/American Heart Association Task Force on Practice Guidelines (ACC/AHA/ASE Committee to Update the 1997 Guidelines for the Clinical Application of Echocardiography). Journal of the American Society of Echocardiography, 16, 1091-1110.

[12] Nagueh, S.F., Appleton, C.P., Gillebert, T.C., Marino, P.N., Oh, J.K., Smiseth, O.A., Waggoner, A.D., Flachskampf, F.A., Pellikka, P.A. and Evangelisa, A. (2009) Recommendations for the Evaluation of Left Ventricular Diastolic Function by Echocardiography. European Journal of Echocardiography, 10, 165-193.

http://dx.doi.org/10.1093/ejechocard/jep007

[13] Schoenfeld, D.A. (1983) Sample-Size Formula for the Proportional-Hazards Regression Model. Biometrics, 39, 499503. http://dx.doi.org/10.2307/2531021

[14] DeLong, E.R., DeLong, D.M. and Clarke-Pearson, D.L. (1988) Comparing the Areas under Two or More Correlated Receiver Operating Characteristic Curves: A Nonparametric Approach. Biometrics, 44, 837-845. http://dx.doi.org/10.2307/2531595

[15] Senni, M., Parrella, P., De Maria, R., Cottini, C., Böhm, M., Ponikowski, P., Filippatos, G., Tribouilloy, C., Di Lenarda, A., Oliva, F., Pulignano, G., Cicoira, M., Nodari, S., Porcu, M., Cioffi, G., Gabrielli, D., Parodi, O., Ferrazzi, P. and Gavazzi, A. (2013) Predicting Heart Failure Outcome from Cardiac and Comorbid Conditions: The 3C-HF Score. International Journal of Cardiology, 163, 206-211. http://dx.doi.org/10.1016/j.ijcard.2011.10.071

[16] Wang, T.J., Larson, M.G., Levy, D., Vasan, R.S., Leip, E.P., Wolf, P.A., D’Agostino, R.B., Murabito, J.M., Kannel, W.B. and Benjamin, E.J. (2003) Temporal Relations of Atrial Fibrillation and Congestive Heart Failure and Their Joint Influence on Mortality: The Framingham Heart Study. Circulation, 107, 2920-2925. http://dx.doi.org/10.1161/01.CIR.0000072767.89944.6E

[17] Mountantonakis, S.E., Grau-Sepulveda, M.V., Bhatt, D.L., Hernandez, A.F., Peterson, E.D. and Fonarow, G.C. (2012) Presence of Atrial Fibrillation Is Independently Associated with Adverse Outcomes in Patients Hospitalized with Heart Failure: An Analysis of Get with the Guidelines-Heart Failure. Circulation: Heart Failure, 5, 191-201. http://dx.doi.org/10.1161/CIRCHEARTFAILURE.111.965681

[18] Chamberlain, A.M., Redfield, M.M., Alonso, A., Weston, S.A. and Roger, V.L. (2011) Atrial Fibrillation and Mortality in Heart Failure: A Community Study. Circulation: Heart Failure, 4, 740-746. http://dx.doi.org/10.1161/CIRCHEARTFAILURE.111.962688

[19] Mamas, M.A., Caldwell, J.C., Chako, S., Garratt, C.J., Fath-Ordoubadi, F. and Neyses, L. (2009) A Meta-Analysis of the Prognostic Significance of Atrial Fibrillation in Chronic Heart Failure. European Journal of Heart Failure, 11, 676-683. http://dx.doi.org/10.1093/eurjhf/hfp085

[20] Linssen, G.C., Rienstra, M., Jaarsma, T., Voors, A.A., van Gelder, I.C., Hillege, H.L. and van Veldhuisen, D.J. (2011) Clinical and Prognostic Effects of Atrial Fibrillation in Heart Failure Patients with Reduced and Preserved Left Ventricular Ejection Fraction. European Journal of Heart Failure, 13, 1111-1120. http://dx.doi.org/10.1093/eurjhf/hfr066

[21] Rossi, A., Dini, F.L., Faggiano, P., Agricola, E., Cicoira, M., Frattini, S., Simioniuc, A., Gullace, M., Ghio, S., Enriquez-Sarano, M. and Temporelli, P.L. (2011) Independent Prognostic Value of Functional Mitral Regurgitation in Patients with Heart Failure. A Quantitative Analysis of 1256 Patients with Ischaemic and Non-Ischaemic Dilated Cardiomyopathy. Heart, 97, 1675-1680. http://dx.doi.org/10.1136/hrt.2011.225789

[22] Lund, L.H. and Mancini, D.M. (2008) Peak $\mathrm{VO}_{2}$ in Elderly Patients with Heart Failure. International Journal of Cardiology, 125, 166-171. http://dx.doi.org/10.1016/j.ijcard.2007.10.004

[23] Scardovi, A.B., Coletta, C., De Maria, R., Perna, S., Aspromonte, N., Feola, M., Rosso, G., Greggi, M. and Ceci, V. (2007) The Cardiopulmonary Exercise Test Is Safe and Reliable in Elderly Patients with Chronic Heart Failure. Journal of Cardiovascular Medicine (Hagerstown), 8, 608-612. http://dx.doi.org/10.2459/01.JCM.0000281698.53983.4e

[24] Elmariah, S., Goldberg, L.R., Allen, M.T. and Kao, A. (2006) Effects of Gender on Peak Oxygen Consumption and the Timing of Cardiac Transplantation. Journal of the American College of Cardiology, 47, 2237-2242. http://dx.doi.org/10.1016/j.jacc.2005.11.089 
[25] Corrà, U., Mezzani, A., Giordano, A., Pistono, M., Gnemmi, M., Caruso, R. and Giannuzzi, P. (2013) Peak Oxygen Consumption and Prognosis in Heart Failure: $14 \mathrm{~mL} / \mathrm{kg} / \mathrm{min}$ Is Not a "Gender-Neutral” Reference. International Journal of Cardiology, 167, 157-161. http://dx.doi.org/10.1016/j.ijcard.2011.12.055

[26] Guazzi, M., Arena, R. and Myers, J. (2006) Comparison of the Prognostic Value of Cardiopulmonary Exercise Testing between Male and Female Patients with Heart Failure. International Journal of Cardiology, 113, 395-400. http://dx.doi.org/10.1016/j.ijcard.2005.11.105

[27] Scardovi, A.B., De Maria, R., Ferraironi, A., Gatto, L., Celestini, A., Forte, S., Parolini, M., Sciarretta, S., Ricci, R. and Guazzi, M. (2012) A Case for Assessment of Oscillatory Breathing during Cardiopulmonary Exercise Test in Risk Stratification of Elderly Patients with Chronic Heart Failure. International Journal of Cardiology, 155, 115-119. http://dx.doi.org/10.1016/j.ijcard.2011.02.033

[28] Guazzi, M., Arena, R., Ascione, A., Piepoli, M. and Guazzi, M.D. (2007) Exercise Oscillatory Breathing and Increased Ventilation to Carbon Dioxide Production Slope in Heart Failure: An Unfavorable Combination with High Prognostic Value. American Heart Journal, 153, 859-867. http://dx.doi.org/10.1016/j.ahj.2007.02.034

[29] Arena, R., Myers, J., Abella, J., Peberdy, M.A., Bensimhon, D., Chase, P. and Guazzi, M. (2007) Development of a Ventilatory Classification System in Patients with Heart Failure. Circulation, 115, 2410-2417. http://dx.doi.org/10.1161/CIRCULATIONAHA.107.686576

[30] Corrà, U., Pistono, M., Mezzani, A., Braghiroli, A., Giordano, A., Lanfranchi, P., Bosimini, E., Gnemmi, M. and Giannuzzi, P. (2006) Sleep and Exertional Periodic Breathing in Chronic Heart Failure: Prognostic Importance and Interdependence. Circulation, 113, 44-50. http://dx.doi.org/10.1161/CIRCULATIONAHA.105.543173

[31] Guazzi, M., Myers, J., Peberdy, M.A., Bensimhon, D., Chase, P. and Arena, R. (2008) Exercise Oscillatory Breathing in Diastolic Heart Failure: Prevalence and Prognostic Insights. European Heart Journal, 29, 2751-2759. http://dx.doi.org/10.1093/eurheartj/ehn437

[32] O’Connor, C.M., Whellan, D.J., Lee, K.L., Keteyian, S.J., Cooper, L.S., Ellis, S.J., Leifer, E.S., Kraus, W.E., Kitzman, D.W., Blumenthal, J.A., Rendall, D.S., Miller, N.H., Fleg, J.L., Schulman, K.A., McKelvie, R.S., Zannad, F. and Piña, I.L. (2009) Efficacy and Safety of Exercise Training in Patients with Chronic Heart Failure: HF-ACTION Randomized Controlled Trial. JAMA, 301, 1439-1450. http://dx.doi.org/10.1001/jama.2009.454 